\title{
Recent Advances on Small-Molecule Epidermal Growth Factor Receptor Inhibitors
}

\author{
Bo-Ya Shi, ${ }^{a}$ Ze-Hao Wang, ${ }^{a}$ Xuan-Jun Wang, ${ }^{a, b}$ Jun Sheng, ${ }^{*, a}$ and Cheng-Ting Zi $\mathrm{Z}^{*, a, b}$ \\ ${ }^{a}$ Key Laboratory of Pu-er Tea Science, Ministry of Education, Yunnan Agricultural University, \\ Kunming, Yunnan 650201, China \\ ${ }^{b}$ College of Science, Yunnan Agricultural University, Kunming, Yunnan 650201, China
}

Email: shengj@ynau.edu.cn (J. S.), zichengting@126.com (C. Z.)

\begin{abstract}
The epidermal growth factor receptor (EGFR) is a kind of cell membrane surface receptor with tyrosine kinase activity, which is closely related to the growth, proliferation, differentiation, apoptosis, metastasis and other processes of tumor cells. Targeting EGFR tyrosine kinase inhibitors has become a hot topic for drug development for treatment of non-small-cell cancer (NSCLC). Herein, we summarized recent advances on the targeted therapeutic drugs for NSCLC in recent years.
\end{abstract}

Keywords non-small cell lung cancer, epidermal growth factor receptor, inhibitors

\section{Introduction}

Lung cancer is the most important malignant tumor, and its morbidity and mortality account for the top of all cancers. In China, the incidence and mortality of lung cancer are the first among the urban population. ${ }^{[1]}$ In recent years, the incidence rate of lung cancer has been increasing rapidly. Among the patients, there were more younger people than before. In particular, the treatment of advanced non-small cell lung cancer (NSCLC) suffered from some limitations. Most patients lose the opportunity of surgery, and the side effects of chemotherapy drugs also limit the clinical application. At present, the treatment of lung cancer cell-specific molecules mainly includes: (1) epidermal growth factor receptor (EGFR); (2) vascular endothelial growth factor (VEGF); (3) matrix metal oproteinases (MMPs); (4) echinoderm microtubule-associated protein 4 (EML4)/anaplastic lymphoma kinase (ALK) fusion gene; (5) proto-oncogene K-ras mutation; (6) BRAF gene mutation; (7) C-MET gene amplification; (8) ROS1 fusion mutation; (9) multi-targeted drugs, and so on. ${ }^{[2]}$ Some studies have shown that EGFR expression or high expression is found in approximate $43 \%-89 \%$ of NSCLC patients with lung cancer tissue samples. Therefore, NSCLC molecular therapy with EGFR as the target has attracted widespread attention in the international tumor community.

\section{EGFR structure and function}

EGFR is a membrane surface receptor with tyrosine kinase activity, which is widely present in human epidermal cells and stromal cells. In normal cells, EGFR tyrosine kinase (EGFR-TK) activity is accurately controlled. However, EGFR mutations are the most prevalent in non-small cell lung cancer (NSCLC). ${ }^{[3]}$ EGFR family is also called EGFR tyrosine kinase family, including EGFR (HER-1), erbB-2 (HER-2), erbb-3 (HER-3) and erbb-4 (HER-4). EGFR is the first cell surface receptor directly related to tumorigenesis. It has tyrosine kinase activity and consists of extracellular, transmembrane and intracellular regions. ${ }^{[4]}$ The extracellular domain is composed of 621 amino acid residues at the $\mathrm{N}$-terminal, which is divided into four subdomains I, II, III and IV. This domain is a ligand binding domain, which can bind a variety of ligands with exciting functions, such as EGF, transforming growth factor-2 $\alpha$ and bidirectional regulatory factors. ${ }^{[5]}$ The transmembrane region is a hydrophobic region composed of 23 amino acid residues and has a single $\alpha$ helix structure. It can fix the receptor on the cell membrane. The intracellular region is composed of 542 amino acid residues and is divided into three subregions: juxtamembrane (JM), tyrosine kinase subregion and C-terminal. The first 13 amino acids (645-657) in JM region can mediate intracellular dimerization, and its self-phosphorylation site is at the C-terminal. When the extracellular domain binds to growth factors or other ligands, EGFR dimerization with other members of the family results in phosphorylation of tyrosine kinase in the cell, thus activating various signaling pathways downstream of EGFR, such as MAPK, PI3K/Akt, STAT3 and ATT5, ultimately leading to tumor cell proliferation, escape from apoptosis, invasion and angiogenesis. ${ }^{[6]}$

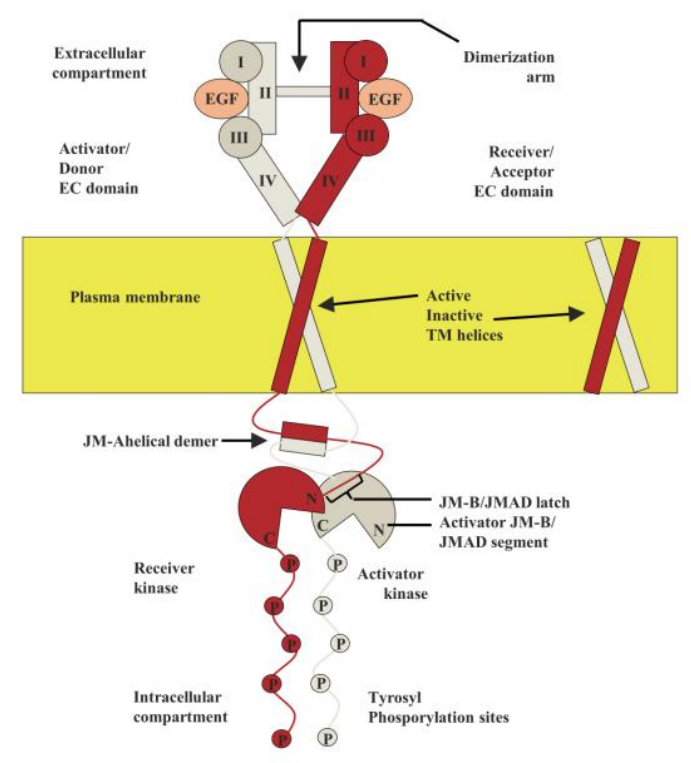

Figure 1 The structural model of epidermal growth factor receptor. 
Table 1 EGFR small molecule tyrosine kinase inhibitors in NSCLC treatment

\begin{tabular}{|c|c|c|c|c|c|}
\hline & Name & Chemical structure & Nuclear structure & Side effects & Ref. \\
\hline \multirow{4}{*}{$1^{\text {st }}$-Generation } & Gefitinib & & 4-Anilinoquinazolines & Rash, diarrhea, pruritus & [7] \\
\hline & Erlotinib & & 4-Anilinoquinazolines & Diarrhea and rash & [8] \\
\hline & Icotinib & & 4-Anilinoquinazolines & Nausea, vomiting, rash & [9] \\
\hline & Lapatinib & & 4-Anilinoquinazolines & Nausea, vomiting, rash & {$[10]$} \\
\hline \multirow{5}{*}{$2^{\text {nd }}-$ Generation } & Afatinib & & 4-Aminoquinazolines & Diarrhea, rash, cardiotoxicity & {$[11]$} \\
\hline & Dacomitin-ib & & 4-Aminoquinazolines & Severe diarrhea and acne & [12] \\
\hline & Neratinib & & 4-Aminoquinazolines & Diarrhea, rash & {$[13]$} \\
\hline & Canertinib & & 4-Aminoquinazolines & Skin penetration, vomiting & {$[14]$} \\
\hline & Pelitinib & & 4-Aminoquinazolines & Diarrhea, rash & {$[15]$} \\
\hline \multirow{4}{*}{$3^{\text {rd }}$-Generation } & WZ-4002 & & "U-type" pyrimidines & Diarrhea, rash & [16] \\
\hline & CO-1686 & & "U-type" pyrimidines & $\begin{array}{l}\text { Hyperglycemia, nausea, } \\
\text { diarrhea }\end{array}$ & {$[16]$} \\
\hline & Osimertinib & & "U-type" pyrimidines & Diarrhea, rash & [17] \\
\hline & HM-61713 & & $\begin{array}{c}\text { Thiophene }[3,2-d] \\
\text { pyrimidines }\end{array}$ & Diarrhea, rash & {$[14]$} \\
\hline \multirow{2}{*}{$4^{\text {th }}$-Generatior } & EAI045 & & Oxyisoindoles & - & [18] \\
\hline & B4020 & & Amino benzimidazoles & - & [19] \\
\hline
\end{tabular}




\section{Recent Advances on EGFR inhibitors}

Clinically, the effective drugs targeting EGFR can be divided into two categories: one is the monoclonal antibody in the extracellular domain of the receptor, which can block the binding between the ligand and the receptor in the extracellular domain of EGFR; the other is the small molecule tyrosine kinase inhibitor (TKI) acting on the receptor cell, which blocks the interaction with ATP through the phosphorylation site of the intracellular segment of the tyrosine kinase that competently binds EGFR. Furthermore, it inhibited the phosphorylation of EGFR and a series of downstream signal transduction. (1) The monoclonal antibody inhibitors of EGFR are cetuximab, panitumumab, nimotuzumab, and so on. The preparation of these monoclonal antibodies is complex, the way of administration is single, and the cost of drugs is high, which seriously limit their clinical applications. (2) Small molecule tyrosine kinase inhibitors can be divided into the first generation of reversible EGFR tyrosine kinase inhibitors, the second generation of irreversible EGFR tyrosine kinase inhibitors and the third generation of non reversible mutation selective EGFR tyrosine kinase inhibitors (Table 1): the first generation EGFR-TKIs (EGFR-19 exon deletion mutation and EGFR-21 exon (L858R substitution mutation)) can inhibit activation and phosphorylation of EGFR domain ATP site through reversible competition, and then inhibit the signal transduction downstream of EGFR: gefitinib, ${ }^{[7]}$ erlotinib, $^{[8]}$ exetane $^{[9]}$ and lapatinib, ${ }^{[10]}$ and so on. The second generation of EGFR-TKIs (the second mutation of EGFR, which is resistant to the first generation of TKIs, including afatini, ${ }^{[11]}$ daptini, ${ }^{[12]}$ lenatinib ${ }^{[13]}$ kanatini $^{[14]}$ and pelletinib ${ }^{[15]}$ ) irreversibly binds to CYS797 in EGFR, CYS805 in HER2 and CYS803 in ErbB4 to inhibit the activity of tyrosine kinase, thus blocking the EGFR-HER2 signal pathway, and ultimately inhibiting tumor proliferation. The resistance mechanism of the third generation EGFR-TKIs (for EGFR mutation and T790M resistance mutation) is C707S mutation in EGFR: wz-4002, ${ }^{[16]} \operatorname{co-1686}^{[16]}$ oxitinib $^{[17]}$ and hm61713. ${ }^{[14]}$ The fourth generation of EGFR-TKIs (for EGFR mutations and T790M resistant mutations) overcame C797S and T790M resistant mutations: eai045 (in clinical) ${ }^{[18]}$ and bi-4020 (in clinical). ${ }^{[19]}$ Hence, the next generation of EGFR TKIs should (1) be highly active against most common EGFR activation mutation del19, (2) not be susceptible to the most common resistance mutations T790M and/or C797S, (3) have low inhibition of EGFRwt to avoid on-target toxicities such as rash and diarrhea, and (4) be highly selective across the human kinome.

\section{Conclusion}

It is a very clear treatment strategy that the function of tumor cells can be controlled by the downstream signal pathway through the inhibition of receptor kinase. However, the drug resistance caused by target mutation poses a new challenge to the research of targeted antitumor drugs. The emergence of irreversible inhibitors provides a new way to solve this problem. Compared with monoclonal antibodies and reversible inhibitors, irreversible inhibitors can prolong the administration time and improve the efficacy. With the further study on the mechanism of action and structure-activity relationship of small-molecular-sized kinase inhibitors, these drugs will become an effective weapon to control advanced NSCLC.

\section{Acknowledgement}

This work was financially supported by the National Nature
Science Foundation of China (Nos. 31960075 and 21602196), the Science and Technology Project of Yunnan Province (Nos. 2017ZF003, 2017FD084, and 2017FG001-046).

\section{Conflict of Interest}

The authors declare no conflict of interest.

Copyright (c) 2020 Bo-Ya Shi, Ze-Hao Wang, Xuan-Jun Wang, Jun Sheng, Cheng-Ting Zi. This article is an open access article distributed under the terms and conditions of the Creative Commons Attribution (CC BY) license (http://creativecommons. org/licenses/by/4.0/). The use, distribution or reproduction in other forums is permitted, provided the original author(s) or licensor are credited and that the original publication in this journal is cited, in accordance with accepted academic practice. No use, distribution or reproduction is permitted which does not comply with these terms.

\section{References}

[1] Chen, W.; Zheng, R.; Zhang, S. Report of cancer incidence and mortality in Cina, 2010. China Cancer 2014, 2, 61.

[2] Han, Z. J.; Deng, S. K. Advances in targeted therapy for non-small cell lung cancer. Qinghai Med. J. 2019, 49, 77-80.

[3] Mcloughlin, E. M.; Gentzler, R. D. Epidermal Growth Factor Receptor Mutations. Thoracic Surg. Clin. 2020, 30, 127-136.

[4] Bishayee, S. Role of conformational alteration in the epidermal growth factor receptor (EGFR) function. Biochem. Pharmacol. 2000, 60, 1217-1223.

[5] Heon, S.; Yeap, B. Y.; Lindeman, N. I.; Joshi V .A.; Butaney, M.; Britt, G. J.; Costa, D. B.; Rabin, M. S.; Jackman, D. M.; Johson, R. E. The impact of initial gefitinib or erlotinib versus chemotherapy on central nervous system progression in advanced non-small cell lung cancer with EGFR mutations. Clin. Cancer Res. 2012, 18, 4406-4414.

[6] Okamoto, I. Epidermal growth factor receptor in relation to tumor development: EGFR-targeted anticancer therapy. FEBS J. 2010 , 277, 309-315.

[7] Mok, T. S.; Wu, Y. L.; Thongprasert, S.; Yang, C. H.; Chu, D. T.; Saijo, N.; Sunpaweravong, P.; Han, B. H.; Margono, B.; Ichinose, Y.; Nishiwaki, Y.; Ohe, Y.; Yang, J. J.; Chewaskulyong, B.; Jiang, H. Y.; Duffield, E. L.; Watkins, C. L.; Armour, A. A.; Fukuoka, M. Gefitinib or Carboplatin-Paclitaxel in Pulmonary Adenocarcinoma. New. Engl. J. Med. 2009, 361, 947-957.

[8] Shepherd, F. A.; Pereira, J. R.; Ciuleanu, T.; Tan, E. H.; Hirsh, V.; Thongprasert, S.; Campos, D.; Maoleekoonpiroj, S.; Smylie, M.; Martins, R.; van Kooten, M.; Dediu, M.; Findlay, B.; Tu, D. S.; Johnston, D.; Bezjak, A.; Clark, G.; Santabárbara, P.; Seymour, L. Erlotinib in previously treated non-small-cell lung cancer. New Engl. J. Med. 2005, 353, 123-132.

[9] Zhao, Q. Effects of icotinib, a novel epidermal growth factor receptor tyrosine kinase inhibitor, in EGFR-mutated non-small cell lung cancer. Oncol. Rep. 2012, 27, 2066-2072.

[10] Blackwell, K. L.; Burstein, H. J.; Storniolo, A. M.; Rugo, H.; Sledge, G.; Koehler, M.; Ellis, C.; Casey, M.; Vukelja, S.; Bischoff, J.; Baselga, J.; O'Shaughnessy, J. Randomized study of lapatinib alone or in combination with trastuzumab in women with ErbB2-Positive, trastuzumab-refractory metastatic breast cancer. J. Clin. Oncol. 2010, 28, 1124-1130.

[11] Agustoni, F.; Platania, M.; Vitali, M.; Zilembo, N.; Haspinger, E. R.; Sinno, V.; Gallucci, R.; Braud, F. D.; Garassino, M. C. Emerging toxicities in the treatment of non-small cell lung cancer: Ocular disorders. Cancer Treat. Rev. 2014, 40, 197-203.

[12] Schleger, C.; Heck, R.; Steinberg, P. The role of wild-type and mutated $\mathrm{N}$-ras in the malignant transformation of liver cells. Mol. Carcinogen. 2000, 28, 31-41. 
[13] Li, D.; Shimamura, T. Bronchial and peripheral murine lung carcinomas induced by T790M-L858R mutant EGFR respond to HKI-272 and rapamycin combination therapy. Cancer Cell 2007, 12, 81-93.

[14] Smaill, J. B.; Showalter, H. D.; Zhou, H.; Bridges, A. J.; McNamara, D. J.; Fry, D. W.; Nelson, J. M.; Sherwood, V.; Vincent, P. W.; Roberts, B. J.; Ellitt, W. L.; Denny, W. A. Tyrosine Kinase Inhibitors. 18. 6-Substituted 4-Anilinoquinazolines and 4-Anilinopyrido[3,4-d]pyrimidines as Soluble, Irreversible Inhibitors of the Epidermal Growth Factor Receptor. J. Med. Chem. 2001, 44, 429-440.

[15] Yoshimura, N.; Kudoh, S.; Kimura, T.; Mitsuoka, S.; Matsuura, K.; Hirata, K.; Matsui, K.; Negoro, S.; Nakagawa, K.; Fukuoka, M. EKB-569, a new irreversible epidermal growth factor receptor tyrosine kinase inhibitor, with clinical activity in patients with non-small cell lung cancer with acquired resistance to gefitinib. Lung Cancer 2006, 51, 363-368.

[16] Sequist, L. V.; Goldman, J. W.; Wakelee, H. A.; Camidge, D. R.; Yu, H. A.; Varga, A.; Solomon, B.; Oxnard, G. R.; Ou, S. I.; Papadimitrakopoulou, V. A.; Chao, B. H.; Liu, S. V. Reckamp, K. L.; Spira, A. I.; Piotrowska, Z.; Despain, D.; Karlovich, C.; Yurasov, S.; Soria, J. Efficacy of rociletinib (CO-1686) in plasma-genotyped T790M-positive non-small cell lung cancer (NSCLC) patients (pts). J. Clin. Oncol. 2015, 33, 8001-8001.
[17] Oxnard, G. R.; Ramalingam, S. S.; Ahn, M.; Kim, S.; Yu, H. A.; Saka, H.; Horn, L.; Goto, K.; Ohe, Y.; Cantarini, M.; Frewer, P.; Lahn, M.; Yang, J. C. Preliminary results of TATTON, a multi-arm phase lb trial of AZD9291 combined with MEDI4736, AZD6094 or selumetinib in EGFR-mutant lung cancer. J. Clin. Oncol. 2015, 33, 2509-2509.

[18] Wang S. H.; Song, Y.; Liu, D. L. EAl045: The fouth-generation EGFR inhibitor overcoming T790M and C797S resistance. Cancer Lett. 2017, 385, 51-54.

[19] Engelhardt, H.; Bose, D.; Petronczki, M.; Scharn, D.; Bader, G.; Baum, A.; Bergner, A.; Chong, E.; Dobel, S.; Egger, G.; Engelhardt, C.; Ettmayer, P.; Fuchs, J. E.; Gerstberger, T.; Gonnella, N. C.; Grimm, A.; Grondal, E.; Haddad, N.; Hopfgartner, B.; Kousek, R.; Krawiec, M.; Kriz, M.; Lamarre, L.; Leung, J.; Mayer, M.; Patel, N. D.; Simov, B. P.; Reeves, J. T.; Schnitzer, R.; Schrenk, A.; Sharps, B.; Solca, F.; Stadtmuller, H.; Tan, Z. L.; Wunberg, T.; Zoephel, A.; Mcconnell, D. Start Selective and Rigidify: The Discovery Path toward a Next Generation of EGFR Tyrosine Kinase Inhibitors. J. Med. Chem. 2019, 62, 10272-10293. 